\title{
A paradigm shift in policing: Crime reduction through problem oriented policing
}

\author{
Murat Ozkan ${ }^{1}$
}

\begin{abstract}
The opportunity theories of crime regards opportunity as a root cause and focus attention on the crime rather than the criminal. In the practical crime prevention efforts, this theoretical framework paved the way for innovative policing strategies like problem oriented policing and situational crime prevention. Policy makers and practitioners accept the motivated offender as given and gather the efforts to prevent offenders accessing sufficient means and opportunities for a crime to occur. This paper describes the link between opportunity theories of crime and successful crime reduction efforts stemmed from them. It entails problem oriented policing and situational crime prevention techniques. Crime is not evenly distributed. It concentrates differently on places, offenders and persons. This paper then describes the fundamental discussion of crime distribution on hot places, targets, products, offenders and victims. Major works and findings in the field of environmental criminology is presented by describing hot spots and crime distribution, and crime patterns. The paper finally presents an evaluation of these approaches.
\end{abstract}

Keywords: Crime Opportunity; Problem Oriented Policing; Situational Crime Prevention; Crime Distribution.

\section{Introduction}

Criminology traditionally focused on why crimes are committed and how people become criminals. A relevantly new approach identifies the sine qua non aspects of crime anf presents opportunity as the one factor that is a must for a crime to occur. Opportunity theories of crime, thus extensively studied the crime event and presented valuable information for crime prevention.

Problem oriented policing (POP) is the strategy that has presented promising outcomes in reducing crime. It depends on the systematic, microscopic examination of each specific crime problem and develops responses in light of what is learned from them (Goldstein, 1990). This analysis relies heavily on a relevant body of crime theory that puts the emphasis on crime rather than criminality.

This study examines the shift in criminology from criminal to crime and presents the theoretical framework that regard opportunity as a root cause of crime. It presents the practical crime prevention efforts stemming from this approach. The problem oriented approach is discussed; chemistry of crime is explored with a special focus on how it relates to crime prevention and reduction; POP and situational crime prevention (SCP) will be revisited to further argue their

\footnotetext{
${ }^{1}$ Ph.D., Turkish National Police, mailmurat@gmail.com
} 
focus on the elements of crime and their value for prevention; and "the offender" through the eyes of POP and SCP approaches will be discussed.

\section{Problem Oriented Policing}

Police has long been regarded as a government institution that deals with crime. In fact, it could be argued that this gives police their status as "experts" of their "profession". The traditional approach of police to crime problem was enforcement. Policing has evolved through eras (Kelling and Moore, 1988) used tactics such as preventive patrol, rapid response, criminal investigations, field interrogations, searches (and others) to deal with crime. Policing has undergone dramatic changes since 1970's. Much of it can be attributed to the empirical studies that have shown the traditional strategies of policing were ineffective in dealing with crime problems (Kelling, Pate, Dieckman and Brown, 1974; Trojanowicz, 1983; Kelling 1981). Recent approaches of community policing and problem oriented policing stem from the search to overcome the shortcomings of traditional policing.

Drawing on the early efforts of Goldstein, POP addresses crime prevention problems of police. Goldstein argues that police put too much effort on the organization of department than crime problems they have to solve (Goldstein, 1979). He argues that police should be proactive, rather than reactive; and pay more attention on problems, as opposed to incidents (Goldstein, 1990).

Problems are the collections of incidents that form the underlying conditions which create or increase crime and disorder. Problems could be solved through varying methods. One proposed model is SARA (acronym stands for scanning, analysis, response and assessment). Police would carry out careful analysis of crime problems in order to design a response that would likely work. The key question is this: What would determine the response that is likely to solve the specific problem in that setting? This requires some hypotheses to begin with. Crime theory is supposed to be providing us with these explanations. If police were to choose a theoretical explanation that would attribute crime problems to the child bearing practices that creates differential criminal inclinations, then the response would be explored in parenthood and childe bearing education. These are very distant factors, and it is highly likely that they will be beyond the reach of police. For that matter, it is not surprising at all that problem oriented policing relies on a new wave in criminology that focuses on more tangible crime causes than individual propensities to criminality.

\section{Causes of crime}

Criminological theory mostly focuses on the factors that constrain individuals to engage in crime-factors like individual traits, disorganized communities, association with delinquent peers, and strain. Crime is largely the result of forces beyond an individual's control. Individuals do not chose to engage in crime, but rather their criminal behavior is determined by a variety of individual and social factors. This "deterministic" view of crime has dominated crime theory since the late 1800s.

In short, the central theme of the mainstream criminology was the offender. The question of "why some people are more (or less) inclined to offending" dominated the literature. In order to talk about a "criminal", however, a criminal offense has to be committed. This obviously would require overcoming certain physical requirements. Crime theory has long neglected to study the setting that transforms offending motivation into criminal action. A relevantly new body of crime theory takes this focus off "criminals" and shifts it to the "crime" itself. Rather than the distant factors that generates preoccupation for criminal inclinations, the "new crime theorizing" puts the emphasis on how settings create more opportunities for crime. 
Although these approaches were viewed by some as contradictory, it is important to note that opportunity theories (or environmental criminology) do not deny the causes of criminal inclination that were suggested by other theories. The idea behind is that, whatever the root causes that lead a person to offending, certain elements are "necessary" for a crime to occur. As Felson and Clarke (1998) claim, since no theory could find a "necessary condition for a person to commit crime, opportunity has as much or more claim to being a root cause" since it is sine qua non for crime occurrence.

\section{Opportunity Theories Of Crime}

\subsection{Routine Activity Theory}

According to this theoretical approach, three elements have to converge in time and space for a crime to occur: Motivated offenders must come in contact with suitable targets in the absence of capable guardians. (Cohen and Felson, 1979; Felson, 1998). The supply of suitable targets and the presence of capable guardians are a function of our everyday or "routine activities" (our family, work, leisure, consumption and other activities). The routine activities approach (originally) takes the supply of motivated offenders as given and focuses on the other elements of crime.

A very useful crime analysis and prevention tool is derived from this theory. The crime triangle is consisted of offender, target, and (lack of) guardianship (or features of crime place). The outer edge of the triangle suggests the controllers (or discouragers) for each: handlers that control offenders (Felson, 1986), guardians that protect targets (Cohen and Felson, 1979) and managers that supervise places (Eck, 1994).

In order for a crime to occur, a motivated offender must find a suitable target in the absence of a capable guardian. This formulation clearly underlines the role of opportunity. This means that "crime can increase without more offenders if there are more targets or if offenders can get to targets with no guardians present" (Felson and Clarke, 1998).

\subsection{The Rational Choice Perspective}

The rational choice perspective argues that "crime is broadly the result of rational choices based on analyses of anticipated costs and benefits" (Cornish and Clarke, 1986). Offending is purposive, and offenders (although limited) make calculations of benefits, gains, and risks. The offender's calculus does not take into account the remote gains and pains, think about the immediate ones available. In order to understand what choices offenders make, it is important to study very specific types of crime.

Rational choice perspective offers to think criminal or to "see the world from the offender's perspective" (Felson and Clarke, 1998).

\subsection{Crime Pattern Theory}

Crime pattern theory, considers how targets come to the attention of offenders and how this effects the distribution of crime events in time and space. The theory links places to targets, and proposes that not all crime opportunities will be available to offenders. Most of the offenders will not go out of the edges to seek for more opportunity, but rather operate in the boundaries that they made themselves familiar in their non-criminal life. Where people work, reside or travel, therefore, would have an impact on how targets come to the attention of offenders (or how offenders find their targets), and this will define local crime patterns (Brantingham and Brantingham, 1993). Offenders look for crime opportunity around the nodes, and along the paths. The significance of this theorizing (for this paper) is that it shows that opportunity plays an important role when 
compared to "motivation" or "criminal inclination". Criminal incidents would not gather around the offenders environment if the motivation was the sole factor for offending.

\subsection{Situational Crime Prevention}

Situational crime prevention approach provides a framework for intervention. Cornish and Clarke (2003) have identified 5 main ways in which situations can be modified. A five by five matrix creates 25 techniques. The main categories are:

- increasing the effort the offender must make to carry out the crime.

- Increasing the risks the offender must face in completing the crime.

- Reducing the rewards or benefits the offender expects to obtain from the crime.

- Removing excuses that offenders may use to "rationalize?" or justify their actions.

- Reducing or avoiding provocations that may tempt or incite offenders into criminal acts.

Similar to problem oriented policing, situational crime prevention relies heavily on opportunity and rational choice theories. The literature of these two approaches -POP and SCPoften overlap, indeed, in recent years they have converged.

\section{Discussing the Role of Opportunity}

Opportunity as a root cause approach draws some common form of criticism. The single most cited one is the "it is people" claim. In short, there is an understanding that even if you protect a target in one place, offenders can and will find another to attack. This proposes that motivation will prevail over opportunity. This claim can not be experimented (due to the simple fact that it is unacceptable to increase crime for that matter), but minor aggressions are tested. Researchers "gave children the opportunity to cheat on tests, to lie about cheating, and to steal coins from puzzles used. Other researchers have scattered stamped and addressed letters in the streets, some containing money, to see if these were mailed" (Clarke and Eck, 2005). The results confirm the causal role of opportunity. Most of the subjects, who (if not find the opportunities) would not do those wrongdoings, could not resist the temptation. A well known and cogent response to opportunity critiques comes from Clarke and Mayhew's suicide study in England (1988). Although it is regarded to be highly influenced by motivation, they demonstrated that the use of less lethal domestic gas in England, have resulted in less number of suicides as the opportunity were removed.

Skeptics about the role of opportunity often claim it is an explanation for common property offenses. If this is true, than its' value would undoubtedly diminish, and it will no longer a promising explanation for crime prevention policies. Thanks to the crime reduction efforts and to the increasing number of scholars world wide, it is shown in a lot of occasions that reducing opportunities would result in a decline in crime. Opportunity reduction techniques were applied to several crime types- property offenses, drug use, gang violence, grafitti, etc, and studies show success in crime reduction. (For several examples, see. "Center for Problem Oriented Policing" web site. www.popcenter.org; and Clarke, 1997).

From the prevention aspect, combination of opportunity theories would create rationale to think that the design and management of cities, neighborhoods, and criminogenic places, have an effect of crime. By altering these, the chemistry of crime could be altered. In other words, by manipulating the elements that are necessary for a crime to occur, it will be possible to reduce crime (although offending motivation is untouched). This reduction in crime will possibly mean less criminals, meaning, if not find the opportunity, some inclined persons will not actually commit a crime. 
It also needs to be implied that opportunity reduction strategies do think about offenders, but not through motivation. Thinking about criminal decision making, crime choices, what offenders seek are central to this approach. For instance, 25 techniques of SCP include denying benefits. Sloan-Howitt and Kelling (1997) reports how level of graffiti in New York City subway cars were reduced by a Clean Car program that aimed to clean off the graffiti immediately. This intervention has reduced the reward of the offense. The graffiti artist wanted their work to be seen all around the city, and the intervention took that pleasure away from them by denying the benefits of the crime. As a result, artists probably calculated the efforts they spend and the benefits they get. This ratio was not in favor of them, and they stopped painting train cars.

Referring to the introduction, it now makes more sense why POP relies on opportunity theories and focus on crime instead of criminality. If the aim is to reduce crime by intervention, it is logical to design a response to alter the situations that create opportunities, instead of intervening with individuals' psychological predispositions to offending or sociological factors that influence crime. We will further analyze crime reduction with a special focus on crime place.

\section{Crime Distribution: Hot Products, Targets, and Places}

\subsection{Hot Products}

Crime concentrations differ for places, offenders, and persons. Not surprisingly, some products are stolen more than others. As it is true for places and targets, products also create different opportunities for criminal activity. What items appeal to thieves? If motivation for stealing is enough to explain theft, why do we see a clustering of crime around some products?

Two acronyms are repeatedly cited in the literature. The first is VIVA which stands for: value, inertia, visibility an access. If a target is (from offender's view) valuable, light enough to carry, visible and accessible easily, that constitutes a suitable target (Cohen and Felson, 1979).

Another acronym is CRAVED, which stands for: Concealable, Removable, Available, Valuable, Enjoyable, Disposable (Clarke, 1999). A similar acronym, EVIL DONE is created by Clarke and Nemwan (2006) to explain the characteristic of suitable terror targets from an opportunity reduction perspective.

\subsection{Crime Victims}

Crime is not distributed equally among offenders. It is true for targets (persons, household, or organizations) as well. Some people, or targets are repeatedly victimized. Does opportunity play a role here? Why would a burglar return to the very same house after a couple weeks?

It is more relevant to discuss the preventive value of repeat victimization phenomenon than to cite ever growing findings for different types of crimes. If victimization is a predictor of future victimization, then protecting those victimized targets might have a preventive value. For example, overall burglary could be reduced by reducing repeats (Forrester et al., 1998)

Furthermore, if offenders who are responsible for repeats could be identified, this could lead a substantial drop in that particular type of crime in that setting. Pease and Laycock (1996) labels the repeat victim as the most precise hot spot- a hot dot. Prevention value of a hot spot would be far more evident in a hot dot.

\subsection{Crime Place : Hot Spots and Risky Facilities}

Crime occurs due to the combination of essential elements in same time and space. Whatever the cause, there is a place, a setting, that crime event occurs. The responsibility of crime may not always be on the offender. This might seem very controversial from the criminal law point of view 
but to better understand how crime occurs, and how it is concentrated among places, persons, and products, will provide us with knowledge to intervene. Studying crime place will also provide us with the interplay of the offender and opportunities, and crime reduction policies can be based on this "role" played by places.

An approach that focuses on criminality may not find it important but from an opportunity perspective, crime place is not just a requirement for a crime to occur, it can also increase the likelihood of crime. Studying place is a direct answer to the question of how instead of why. Even the highly motivated offender has to establish a crime setting. In the opportunity framework, place is not the city or the neighborhoods (as they were the unit of analysis in earlier ecological studies of Park and Burgess, 1921; Shaw and McKay, 1942). Unlike these macro level units, crime place is the smallest unit of analysis where an actual crime occurs. These can be as small as "the area immediately next to an automatic teller machine or as large as a block face, a strip shopping center, or an apartment building. Often, places are thought of as addresses, specific types of businesses, or blockfaces" (Eck and Weisburd, 1995, p.3).

Crime place literature shows that, similar to the irregular distribution of crime among offenders, crime is not equally distributed among places. Some people do not commit a crime, some do. In fact, literature presents evidence that small proportions of offenders are responsible for very large proportions of criminal activity. Is it true for crime places? In fact, it is true to a degree that the crime concentrations for "repeat" places are heavier than it is among repeat offenders. Why would some places see more crime than others? The answer is in the characteristics of the settings that either attracts or generates crime by providing opportunities.

Sherman (1995) cites the famous cohort study (of Wolfgang, Figlio and Sellin, 1972), and reports that the domestic violence concentration among places in Minneapolis is six times greater than it is among persons (3\% of the places generates $50 \%$ of the calls, whereas in Wolfgang's study, $18 \%$ of offenders produced $50 \%$ of arrests).

What do these findings tell about crime prevention policy? Sherman (1995, p.37) answers it by actually asking a simple question: "For if future crime is six times more predictable by the address of the occurrence than by the identity of the offender, why aren't we doing more about it? Why aren't we thinking more about wheredunit, rather than just whodunit?"

The crime concentration principle also holds true for "facilities". Clarke and Eck (2007) draw attention to how crime is concentrated in some small numbers of pubs, convenience stores, gas stations, and schools and other. For example, they report that $4 \%$ of bus routes in Merseyside "experienced 80 percent of all reported crime incidents on bus routes and that about 5 percent of bus stops experienced nearly 30 percent of vandal attacks".

Why are some places more risky than others? In response to this fundamental question, Clarke and Eck provide some criteria to be able to identify risky places: size, hot products, location, repeat victimization, poor design and managements of facilities. First, everything being equal, larger facilities are more likely to report crime or disorder than smaller facilities. For example, Clarke and Eck cites study done in Danvers, Massachusetts indicating that most shoplifting occurred in one of the largest store in the city. Second, it is inevitable for a store that primarily sells small high value electronic items to attract more shoplifters than a grocery store. Third, facilities in areas with high reported crimes and a large volume of calls for police intervention will be more likely to be vulnerable to victimization than facilities in low crime areas. Repeat victimization is the fourth variable in identifying risky facilities. Some facilities, by their very nature, might attract people who are vulnerable to victimization. For example, a place that provides various services to elderly people might be picked up by motivated offenders for various kinds of crimes ranging from assault to robbery. 
In sum, regardless of the offender motivation, opportunity plays a central role on where and how crimes are committed.

\section{Conclusion}

Science has to address real life problems. Criminologists should be able to find plausible explanations for crime problems. Opportunity theories do this better than many other theoretical explanations. They don't aim to improve human character. They underline the role of opportunity as a root cause of "crime" and they are not distracted by the exploring of criminal dispositions. This is a shift from the mainstream view of criminology: A shift from criminality to crime. When you change the fundamental question from who, or why, to how; it brings other dimensions to the table. For the preventive point of view, this new approach bridges the gap between crime theory and crime problems. Not only it bridges the gap, but it may pave the way for a science and practice marriage. Problem oriented policing and situational crime prevention are the fruits of this marriage.

The ultimate goal of problem oriented policing should be crime prevention and reduction. It has to provide practical, tangible solutions to real crime problems. This requires altering the conditions that lead to crime. It is therefore not surprising that he underlying theoretical framework emphasizes the physical requirements of a crime rather than the childhood, parenting, family ties, or biological treats of offenders. Police would definitely find opportunity reduction strategies a lot simpler and promising. Detecting crime concentration areas, analyzing repeat victimization are in the hands of police when compared to dealing with distant root causes.

Problems or shortcomings of problem oriented policing are present. This is not the focus of this paper however. As many scholars point out, the weakest link (and probably the most important) of the approach is the analysis of the problems. Another danger is the poor implementation of the concept that would actually diminish its' value and status. Nevertheless, opportunity reduction strategies have shown enough success. We can be hopeful of the future of problem oriented policing, if we can get police departments into it. Better implementations would be created, because it has a very strong theoretical underpinning: opportunity makes the thief?

\section{References}

Brantingham, Patricia and Paul (1993). Environment, Routine, and Situation: Toward a Pattern Theory of Crime. Routine Activity and Rational Choice, Advances in Criminological Thoery, volume 5, edited by Ronald Clarke and Marcus Felson. New Brunswick, NJ: Transaction Publishers.

Clarke, Ronald V. (1997). Situational Crime Prevention: Successful Case Studies. Albany, NY: Harrow and Heston.

Clarke, Ronald. V. (1999) Hot products: Understanding, anticipating and reducing demand for stolen goods. Home Office Research, Development and Statistics Directorate, London. http://www.homeoffice.gov.uk/rds/prgpdfs/fprs112.pdf

Clarke, R.V.G. and P. Mayhew (1988). British gas suicide story \& its criminological implications. Crime. and Justice 10:107

Clarke, R.V and J. Eck (2005) Crime Analysis for Problem Solvers in 60 Small Steps. Office of Community Oriented Policing Services. Washington, DC: US Department of Justice.

Clarke, R.V. and G. Newman (2006). Outsmarting the Terrorists. Westport, CT: Praeger Security International

Clarke, R. V., \& Eck, J. E (2007). Understanding risky facilities. U.S. Department of Justice: Office of Community Oriented Policing Services 

of Human Sciences, 13(1), 2032-2039. doi:10.14687/ijhs.v13i1.3764

Cohen, L.E., \& Felson, M. (1979). Social Change and Crime Rate Trends: A Routine Activity Approach. American Sociological Review 44 (4): 588-608

Cornish, D.B., \& Clarke,R.V. (Eds.). (1986). The Reasoning Criminal: Rational Choice Perspectives on Offending. New York: Springer-Verlag.

Cornish, D. and Clarke, R.V. (2003) Opportunities, Precipitators and Criminal Decisions: A Reply to Wortley's Critique of Situational Crime Prevention. In: M. Smith and D.B. Cornish (eds.), Theory for Situational Crime Prevention. Crime Prevention Studies, Vol. 16. Monsey, NY: Criminal Justice Press

Eck, John.E. (1994). Drug Markets and Drug Places: A Case-Control Study of the Spatial Structure of Illicit Drug Dealing. Doctoral dissertation, University of Maryland, College Park.

Eck, J. \& Weisburd, D. (eds.) (1995). Crime and Place. Crime Prevention Studies Vol. 4. Monsey, NY: Criminal Justice Press.

Felson, M. (1986). Routine Activities, Social Controls, Rational Decisions, and Criminal Outcomes. In: D. Cornish and R.V.G. Clarke (eds.), The Reasoning Criminal. New York, NY: SpringerVerlag.

Felson, M. \& Clarke, R. V. (1998). Opportunity Makes the Thief: Practical Theory for Crime Prevention. Police Research Series, Paper 98. Policing and Reducing Crime Unit, Research, Development and Statistics Directorate.. London: Home Office. [www.homeoffice.gov.uk/rds/prgpdfs/fprs98.pdf]

Forrester D., M. Chatterton and K. Pease (1988). The Kirkholt Burglary Prevention Project, Rochdale. (Crime Prevention Unit Paper \#13.) London, UK: Home Office.

Goldstein, H. (1979). Improving policing: A problem-oriented approach. Crime and Delinquency, 236-58.

Goldstein, H. (1990). Problem-Oriented Policing. Philadelphia, Pennsylvania: Temple University Press.

Kelling, G.L.,\& Moore, M.H. (November, 1988). The Evolving Strategy of Policing. Perspectives on Policing(5)

Kelling, G. L., Pate, T., Dieckman, D, \& Brown, C. (1974) The Kansas City Preventive Patrol Experiment: Technical Report. Police Foundation, Washington, DC.

Kelling, G.L. (1981) The Newark Foot Patrol Experiment. Washington, D.C.: Police Foundation.

Park, R. E., \& Burgess, E. W. (1921). Introduction to the science of sociology. Chicago, Illinois: University of Chicago Press

Shaw, Clifford R. \& McKay, Henry D. (1942). Juvenile Delinquency in Urban Areas. Chicago: University of Chicago Press.

Sherman, L. (1995). Hot Spots of Crime and Criminal Careers of Places. In John Eck and David. Weisburd (eds.), Crime and Place: Crime Prevention Studies, vol 4. Monsey: NY.

Spelman, W. and J.E. Eck (1989). Sitting Ducks, Ravenous Wolves, and Helping Hands: New Approaches to Urban Policing. Public Affairs Comment 35:1-9.

Trojanowicz, R. C. (1983) An Evaluation of a Neighborhood Foot Patrol Program Journal of Police Science and Administration 11, p.410-419.

Wolfgang, M.E., R. Figlio and T. Sellin (1972). Delinquency in a Birth Cohort. Chicago, IL: University of Chicago Press. 